\title{
Partial p16 staining in oropharyngeal squamous cell carcinoma: extent and pattern correlate with human papillomavirus RNA status
}

James S Lewis Jr ${ }^{1,2}$, Rebecca D Chernock ${ }^{1,2}$, Xiao-Jun $\mathrm{Ma}^{3}$, John J Flanagan ${ }^{3}$, Yuling Luo ${ }^{3}$, $\mathrm{Ge} \mathrm{Gao}^{4}$, Xiaowei Wang ${ }^{4}$ and Samir K El-Mofty ${ }^{1}$

${ }^{1}$ Department of Pathology and Immunology, Washington University, St Louis, MO, USA; ${ }^{2}$ Department of

Otolaryngology, Head and Neck Surgery, Washington University, St Louis, MO, USA; ${ }^{3}$ Advanced Cell

Diagnostics, Hayward, CA, USA and ${ }^{4}$ Department of Radiation Oncology, Washington University,

St Louis, MO, USA

Human papillomavirus (HPV)-related oropharyngeal squamous cell carcinoma has unique biology and better outcomes. p16 immunostaining is used as a surrogate marker for transcriptionally active HPV. Although diffuse staining is generally accepted as positive, the significance of partial staining has not been established, nor has the cutoff for extent of p16 staining that should be used to identify a tumor as HPV-related. From three other large studies utilizing p16 immunohistochemistry, we identified all cases with partial positive staining. The p16-stained slides were reviewed by three study pathologists for staining (nuclear and cytoplasmic) extent (in quartiles), and also for percentage that was confluent (ie, back-to-back cell staining). Tumors were histologically typed (keratinizing, non-keratinizing, or non-keratinizing with maturation) and tested for high-risk HPV by RNA in-situ hybridization and reverse-transcriptase PCR. For the 16 cases, there were two $4+(13 \%)$, five $3+(31 \%)$, six $2+(38 \%)$, and three $1+(19 \%)$ p16 staining tumors. Extent of staining ranged from 5 to $90 \%$ of cells positive with $25 \%$ or more confluent staining in $4 / 16(25 \%)$. Of the $16(31 \%)$ cases, 5 were HPV-related on the basis of RNA in-situ hybridization and reverse-transcriptase PCR. All of these cases had $>50 \%$ p16 staining, $4 / 5$ $(80 \%)$ had more than $25 \%$ confluent staining, and $4 / 7(57 \%)$ had non-keratinizing histological features. Only one of the p16 1+/2 + tumors was HPV RNA-positive (by reverse-transcriptase PCR only and low level). All $1+/ 2+$ cases were keratinizing type or undifferentiated. By sensitive detection methods, most partial p16-positive squamous cell carcinoma cases with $>\mathbf{5 0} \%$ staining harbor transcriptionally active HPV, and most HPV + tumors have significant amounts of confluent staining. Cases with $<\mathbf{5 0} \%$ p16 staining and lacking significant confluent staining rarely harbor HPV. These results support that greater than $75 \%$ p16 staining or, alternatively, $>50 \%$ staining combined with $>25 \%$ confluent areas, are suitable cutoffs for defining positivity. Modern Pathology (2012) 25, 1212-1220; doi:10.1038/modpathol.2012.79; published online 18 May 2012

Keywords: human papillomavirus; oropharyngeal squamous cell carcinoma; p16 immunohistochemistry

\section{Introduction}

Over the past several decades, a distinct type of oropharyngeal squamous cell carcinoma has emerged, which is associated with transcriptionally

Correspondence: Dr JS Lewis Jr, MD, Departments of Pathology and Immunology, and Otolaryngology, Washington University School of Medicine, Campus Box 8118, 660 South Euclid Avenue, St Louis, MO 63110, USA.

E-mail: jlewis@path.wustl.edu

Received 19 February 2012; revised 4 March 2012; accepted 4 March 2012; published online 18 May 2012 active, high-risk (HR) human papillomavirus (HPV). ${ }^{1-4}$ These tumors are increasing in incidence despite the overall decrease in head and neck squamous cell carcinoma, in what has been termed a cancer 'epidemic. ${ }^{5,6}$

The molecular characteristics, biology, and clinical behavior of HPV-related oropharyngeal squamous cell carcinomas have been elucidated over the past several decades as well. ${ }^{3,7}$ The tumors are more common in Caucasian men who are younger than typical head and neck squamous cell carcinoma patients, have less exposure to cigarette smoke, and 
have higher numbers of sex partners, and greater oral sex exposure than non-HPV-related cancer patients. ${ }^{5,8,9}$ They frequently present with large neck masses with small, or even frequently clinically undetectable, primary tumors ${ }^{1,10,11}$ that tend to have a non-keratinizing morphology, ${ }^{12}$ and that are genetically less complex than non-HPV-related squamous cell carcinomas. Specifically, tumors have less gross chromosomal aberrations, rarely harbor p53 mutations, ${ }^{13}$ and have approximately one half the mutation rate of non-HPV-related squamous cell carcinoma. ${ }^{14}$ The most important difference for patients with these tumors, though, is that their prognosis is significantly better than for patients whose tumors are not related to transcriptionally active HPV. ${ }^{1,15-18}$

Identification of groups of patients who have this prognostically favorable HPV-related squamous cell carcinoma type is becoming increasingly important in clinical practice ${ }^{19,20}$ for patient counseling, and in the near future, will be used as the basis for different treatment. The identification of HPV in patients' tumors correlates strongly with improved prognosis. ${ }^{111,18,21,22}$ To clearly distinguish between tumors that are HPV-related and those that are not can be complicated, however. HPV-specific tests include DNA-based PCR, ${ }^{21,23}$ DNA in-situ hybridization, ${ }^{1,18}$ reverse-transcriptase PCR for E6 and E7 mRNA, ${ }^{20,24}$ and more recently, RNA in-situ hybridization. ${ }^{25}$ DNA in-situ hybridization is the most widely available in clinical practice, but it lacks sensitivity and also can be difficult to interpret. Tests that assess for transcriptionally active HPV, such as reverse-transcriptase PCR or RNA in-situ hybridization for HPV mRNA are probably the most sensitive and specific, but are technically difficult to perform and have limited availability. As the HPV protein E7 degrades the retinoblastoma protein leading to aberrant overexpression of p16, p16 immunohistochemistry has also been shown to be a sensitive surrogate test for the presence of transcriptionally active HPV particularly in oropharyngeal squamous cell carcinoma. In addition, p16 immunohistochemistry is widely available and easy to interpret. For HPV identification and risk stratification, many advocate for p16 immunohistochemistry as a screening test to be followed by, when positive, an HPVspecific test, such as DNA in-situ hybridization or PCR, or potentially both. ${ }^{11,26-30}$ There is an emerging view, however, that the strong risk stratification for patient survival provided by p16 immunohistochemistry in oropharyngeal squamous cell carcinoma, combined with simplicity and wide availability, make it a very suitable single marker for risk stratification and patient counseling about the nature of the disease and the expected prognosis.

For p16 to be used alone, or even in combination with other tests, criteria for positivity need to be clearly established. Although most oropharyngeal squamous cell carcinoma are clearly positive (strong and diffuse immunoreactivity) (Figure 1) or negative (no immunoreactivity) for p16, a minority of cases have partial staining, ${ }^{1131,32}$ and little direct evidence exists in the literature to define what cutoff or pattern correlates with the presence of transcriptionally active HPV (and favorable biology), and thus should be considered positive. We examined a small cohort of partially p16-positive oropharyngeal squamous cell carcinoma cases from three large databases, characterized their extent, intensity, and pattern of p16 staining, and compared these with their morphology and with tests for HR HPV DNA and E6/E7 mRNA.

\section{Materials and methods}

From three larger studies ${ }^{10,11}$ of over 400 oropharyngeal squamous cell carcinoma patients, those which were noted to have partial p16 staining (between 0 and $75 \%$ of tumor cells) were collected. The hematoxylin and eosin slides were reviewed by three study pathologists and histologically typed using our previously reported typing system ${ }^{11,12}$ into keratinizing squamous cell carcinoma (Type 1), nonkeratinizing squamous cell carcinoma with maturation (Type 2), and non-keratinizing squamous cell carcinoma (Type 3). Others specific variants were diagnosed on the basis of their published features as defined by the WHO Classification of Head and Neck Tumours. ${ }^{33,34}$ Clinical and pathological information on all patients were obtained from electronic medical records.

\section{p16 Immunohistochemistry}

Immunohistochemistry was performed on representative $4 \mu \mathrm{m}$ sections cut from formalin-fixed, paraffin-embedded tissue blocks, using a monoclonal antibody to p16 (MTM Laboratories; monoclonal; $1: 1$ dilution) on a Ventana Benchmark LT automated immunostainer (Ventana Medical Systems, Tucson AZ, USA) according to standard protocols. Detection involved Ventana's ultraView Universal DAB Detection Kit that utilizes a cocktail of enzyme-labeled secondary antibodies that locate the bound primary antibody. The complex is then visualized with hydrogen peroxide substrate and a 3,3 '-diaminobenzidine tetrahydrochloride (DAB) chromogen. No biotin is involved. Antigen retrieval, standard on the machine, utilized the Ventana CC1, EDTA-Tris, pH 8.0 solution. A known p16expressing head and neck squamous cell carcinoma case was used as the positive control and sections of normal tonsil used for negative controls with each run.

Cases were reviewed independently by the three study pathologists (JSL, SKM, RDC) without knowledge of the HPV results, and were classified as follows: $0=$ negative; $1+=1-25 \%$ of tumor cells positive; $2+=26-50 \% ; 3+=51-75 \% ; 4+\geq 76 \%$. The amount of staining was also assessed in increments of $10 \%$. Tumor cells had to have nuclear 
and cytoplasmic staining to be considered positive and were read for distribution of staining regardless of its intensity. The discrepant quartile results were resolved by consensus review, and the actual percentage assessment by each pathologist averaged. The pattern of staining was also assessed for confluence of staining. For confluence, staining in groups of more than 10 tumor cells was considered positive, and then, the overall percentage of p16positive cells that were in confluent groups assessed for their proportion to the overall amount of p16positive cells (Figure 2). Results for the three reviewing pathologists were averaged. In addition, cases were classified individually by each pathologist for intensity of staining as weak, moderate, or strong, and the final staining intensity category was again determined by consensus review.

\section{HPV In-Situ Hybridization}

DNA in-situ hybridization was performed using unstained tissue sections using the in-situ hybridization I View Blue Plus Detection Kit (Ventana Medical System) according to the manufacturer's instructions. The assay utilized the Ventana HPV III Family 16, Probe B, a cocktail recognizing a cocktail of HR HPV. Cases were read independently by three pathologists (JSL, SKM, RDC) without knowledge of the other test results, and were classified in a binary manner as either positive or negative. Any blue nuclear dots were considered positive. Discrepant cases were resolved by consensus review.

In-situ hybridization for HR HPV E6/E7 RNA was performed manually using the RNAscope HPV kit (Advanced Cell Diagnostics, Hayward, CA, USA) according to the manufacturer's instructions. Briefly, $4 \mu \mathrm{m}$ formalin-fixed, paraffin-embedded tissue sections were pretreated with heat and protease before hybridization with a target probe to the HR HPV genotype 16 (performed on its own individual slide and designated ' 16 ') and target probes to the other HR genotypes 18, 31, 33, 35, 52, and 58 (performed as a cocktail for these 6 types on its own individual slide and designated 'high risk'). An HRP-based signal amplification system was then hybridized to the target probes followed by color development with DAB. Positive staining was identified as brown, punctate dots present in the nucleus and/or cytoplasm. Control probes for the bacterial gene $D a p B$ (negative control) and for the housekeeping gene ubiquitin $C$ (positive control-evidence of adequate RNA) were also included on each case. Cases were read by one study pathologist (JSL) without knowledge of the p16 results, and were classified in a binary manner as either positive or negative. Positive cases had to have granular cytoplasmic and/or nuclear brown staining that was above the signal on the $D a p B$ negative control slide. Negative cases had to have suitable brown granular cytoplasmic staining on the ubiquitin-C-stained slide.

\section{Reverse-Transcriptase PCR Detection of HPV E6/E7 mRNA}

Reverse-transcriptase PCR was performed using RNA extracted from unstained slides for E6 and E7 for the most common 13 HR HPV types $(16,18,31$, 33, 35, 39, 45, 52, 56, 58, 59, 66, and 68). Extraction was with Qiagen miRNeasy formalin-fixed, paraffinembedded tissue kits, and resulted in between 0.5 and $5 \mu \mathrm{g}$ of RNA, depending on tumor size. All oligo primers in the assays were purchased from SigmaAldrich (St Louis, MO, USA). The reverse-transcription reaction was done with the High Capacity cDNA Reverse Transcription Kit (Applied Biosystems). The reverse-transcriptase PCR reaction mixture contained $150 \mathrm{ng}$ of RNA, and was incubated at $25^{\circ} \mathrm{C}$ for $20 \mathrm{~min}, 37^{\circ} \mathrm{C}$ for $60 \mathrm{~min}$, and then $85^{\circ} \mathrm{C}$ for 5 min. Real-time PCR was then performed to quantify the cDNA product using Power SYBR Green PCR Master Mix (Applied Biosystems) and $500 \mathrm{nM}$ HPV type-specific primers. Each HPV assay for E6 or E7 from 13 HPV types was individually performed in a separate well on a 384-well PCR plate. The PCR protocol was $95{ }^{\circ} \mathrm{C}$ for $10 \mathrm{~min}$, and then 36 cycles of amplification $\left(95^{\circ} \mathrm{C}\right.$ for $10 \mathrm{~s}, 58^{\circ} \mathrm{C}$ for $15 \mathrm{~s}$, and $60^{\circ} \mathrm{C}$ for $15 \mathrm{~s}$ ). In addition, GAPDH and $\beta$-actin were included as expression reference controls for real-time PCR data normalization (normalized to the average expression of these two control genes). Quantitation was expressed as normalized $\log _{2}$-scale data compared with the detection-threshold PCR cycle number.

\section{Statistical analysis}

Correlations between categorical variables were analyzed using Fisher's exact tests. For continuous variables, Mann-Whitney testing was utilized. Analyses were performed using GraphPad Prism software (Prism 5 for Windows; Version 5.03).

\section{Results}

There were 16 total cases of oropharyngeal squamous cell carcinoma with partial p16 immunohistochemical staining of tumor cells. The cases were from 1998 to 2011, and patient demographic information is presented in Table 1. Results for p16-staining quantitation, and assessment for confluence, histological typing, and HPV-specific testing are presented in Table 2. There were five p16 $1+$, four $2+$, five $3+$, and two $4+$ cases (Figure 3 ). For simplicity of comparisons, cases were divided into those that were $1+$ and $2+$ (focal p16 staining) versus $3+$ and $4+$ (extensive p16 staining).

There were no significant differences amongst the focal and diffuse p16 groups for the clinical or pathological features. For the p16 diffuse $(3+$ and 4 + ) cases, five of seven $(72 \%)$ were positive for HPV, all for transcriptionally active HPV, and with all 
cases testable being positive by both RNA in-situ hybridization (Figure 1) and reverse-transcriptase PCR. On assessment for confluent staining, four of the seven $(57 \%)$ p16 diffuse $(3+$ or $4+)$ cases showed greater than $25 \%$ of the tumor surface area showing positive staining in cells in a back-to-back distribution (ie, more than just minimal confluent staining). By histological typing, three of seven $(43 \%)$ of the diffuse $(3+$ or $4+)$ cases were nonkeratinizing (Type 3), one of seven (14\%) nonkeratinizing with maturation (Type 2), and three of seven (43\%) keratinizing (Type 1 ).

Table 1 Clinical features of the cases

\begin{tabular}{|c|c|c|c|c|}
\hline Group (no.) & $\begin{array}{l}\text { All } \\
(16)\end{array}$ & $\begin{array}{c}\text { p16 1+ } \\
\text { or } 2+(9)\end{array}$ & $\begin{array}{c}\text { p16 3+ } \\
\text { or } 4+(7)\end{array}$ & $\begin{array}{c}P- \\
\text { value }^{\mathrm{a}}\end{array}$ \\
\hline Age-mean; median & $61.2 ; 57.5$ & $61.4 ; 56.0$ & $60.9 ; 58.0$ & 0.83 \\
\hline \multicolumn{5}{|l|}{ Gender (\%) } \\
\hline Male & $13(81)$ & $7(78)$ & $6(86)$ & \\
\hline Female & 3 (19) & $2(22)$ & $1(14)$ & 1.0 \\
\hline \multicolumn{5}{|l|}{ Smoking (\%) } \\
\hline Yes (current/former) & $15(94)$ & $8(100)$ & $6(86)$ & \\
\hline No (never) & $1(6)$ & $0(0)$ & $1(14)$ & 0.47 \\
\hline \multicolumn{5}{|l|}{ T-stage (\%) } \\
\hline $\mathrm{T} 1 / \mathrm{T} 2$ & $5(31)$ & $3(33)$ & $2(29)$ & \\
\hline $\mathrm{T} 3 / \mathrm{T} 4$ & $11(69)$ & $6(67)$ & $5(71)$ & 1.0 \\
\hline \multicolumn{5}{|l|}{$N$-stage $(\%)$} \\
\hline No & $4(25)$ & $2(22)$ & $2(29)$ & \\
\hline $\mathrm{N} 1,2,3$ & $12(75)$ & $7(78)$ & $5(71)$ & 1.0 \\
\hline \multicolumn{5}{|l|}{ Treatment type (\%) } \\
\hline Definitive XRT & $9(56)$ & $4(44)$ & $4(57)$ & \\
\hline Surgery \pm XRT & $7(44)$ & $5(56)$ & $3(43)$ & 1.0 \\
\hline
\end{tabular}

XRT, radiation therapy.

${ }^{\mathrm{a}} \mathrm{P}$-value represents p16 $1+$ or $2+$ versus p16 $3+$ or $4+$.
Both of the two $4+(>75 \%)$ p16-staining cases were HPV-positive. For the five tumors that had $3+$ (50 to $75 \%$ ) p16 staining, three of them $(60 \%$ ) harbored transcriptionally active HPV by RNA in-situ hybridization (Figure 2) and reversetranscriptase PCR. These three tumors all had confluent p16 staining in $60 \%$ or more of the tumor, whereas the two HPV-negative tumors had confluent staining of only 10 and $20 \%$. Four of the five RNA in-situ-hybridization-positive cases were HPV type 16. The remaining case was positive for a non-HPV 16 HR type.

For the nine p16 $1+$ or $2+$ cases, only one was positive for HPV. This was by reverse-transcriptase PCR, but it showed very low levels of HPV RNA (1.4 times controls versus an average of 5.4 times controls for the other reverse-transcriptase PCRpositive cases). This case was a keratinizing (Type 1) squamous cell carcinoma with only 5\% p16 staining and less than 5\% confluent staining. None of the p16 $1+$ or $2+$ cases had more than just minimal confluent p16 staining (all less than $20 \%$ ). The histological type for all p16 $1+$ and $2+$ cases was either keratinizing (Type 1) squamous cell carcinoma or undifferentiated.

Intensity of the staining was variable, but the $3+$ and $4+$ cases had stronger staining (six of seven classified as strong) than the $1+$ and $2+$ cases (two of nine classified as strong; $P=0.04$ ). However, when dividing cases binarily by the presence of HPV RNA, there was no statistically significant difference in intensity (4 of 6 cases with HPV RNA were strong versus 4 of 10 cases without HPV RNA; $P=0.61$ ).

Considering the histological typing of the tumors, the p16 $3+$ or $4+$ cases were more likely to be nonkeratinizing (Type 3) or non-keratinizing with maturation (Type 2) squamous cell carcinoma as opposed to keratinizing (Type 1) squamous cell

Table 2 Pathological features and staining results for each case

\begin{tabular}{|c|c|c|c|c|c|c|c|c|}
\hline Case & $\begin{array}{l}\text { p16 score } \\
\text { quartile }\end{array}$ & $\begin{array}{l}\text { Histo } \\
\text { type }\end{array}$ & $\begin{array}{l}\text { p16 confluent } \\
\text { staining }\end{array}$ & $\begin{array}{c}\mathrm{p} 16 \\
\text { intensity }\end{array}$ & $\begin{array}{c}\text { ISH for HPV } \\
\text { DNA }\end{array}$ & $\begin{array}{c}\text { ISH for } \\
\text { HPV E6/E7 } \\
\text { RNA }\end{array}$ & $\begin{array}{l}\text { RT-PCR for } \\
\text { HPV E6/E7 } \\
\text { RNA }\end{array}$ & $\begin{array}{c}\text { E6/E7 mRNA } \\
\text { quantitation }\end{array}$ \\
\hline
\end{tabular}

\begin{tabular}{|c|c|c|c|c|c|c|c|c|}
\hline 1 & 1 & 1 & $<5$ & $\mathrm{M}$ & - & - & + & 1.4 \\
\hline 2 & 1 & 1 & 5 & $\mathrm{M}$ & - & - & - & 0 \\
\hline 3 & 1 & 1 & $<5$ & $\mathrm{~S}$ & - & - & - & 0 \\
\hline 4 & 2 & Undiff & 10 & $\mathrm{M}$ & - & - & - & 0 \\
\hline 5 & 2 & Undiff & 20 & W & - & - & - & 0 \\
\hline 6 & 2 & 1 & 10 & $\mathrm{M}$ & - & - & - & 0 \\
\hline 7 & 2 & 1 & 5 & $\mathrm{~S}$ & - & - & - & 0 \\
\hline 8 & 2 & 1 & 5 & $\mathrm{M}$ & - & - & Insuff RNA & n.a. \\
\hline 9 & 2 & 1 & 10 & $\mathrm{M}$ & - & - & - & 0 \\
\hline 10 & 3 & 2 & 80 & $\mathrm{~S}$ & - & + & + & 4.4 \\
\hline 11 & 3 & 1 & 60 & $\mathrm{~S}$ & + & + & Insuff RNA & n.a. \\
\hline 12 & 3 & 1 & 10 & $\mathrm{~S}$ & - & - & - & 0 \\
\hline 13 & 3 & 1 & 20 & $\mathrm{~S}$ & - & - & - & 0 \\
\hline 14 & 3 & 3 & 60 & $\mathrm{~S}$ & + & + & + & 5.6 \\
\hline 15 & 4 & 3 & 20 & $\mathrm{M}$ & + & + & + & 5.7 \\
\hline 16 & 4 & 3 & 80 & $\mathrm{~S}$ & - & + & + & 5.7 \\
\hline
\end{tabular}

Abbreviations: ISH, in-situ hybridization; HPV, human papillomavirus; RT-PCR, reverse-transcriptase PCR; Undiff, undifferentiated carcinoma; Insuff, insufficient; n.a., not applicable; S, strong; M, moderate; W, weak. 


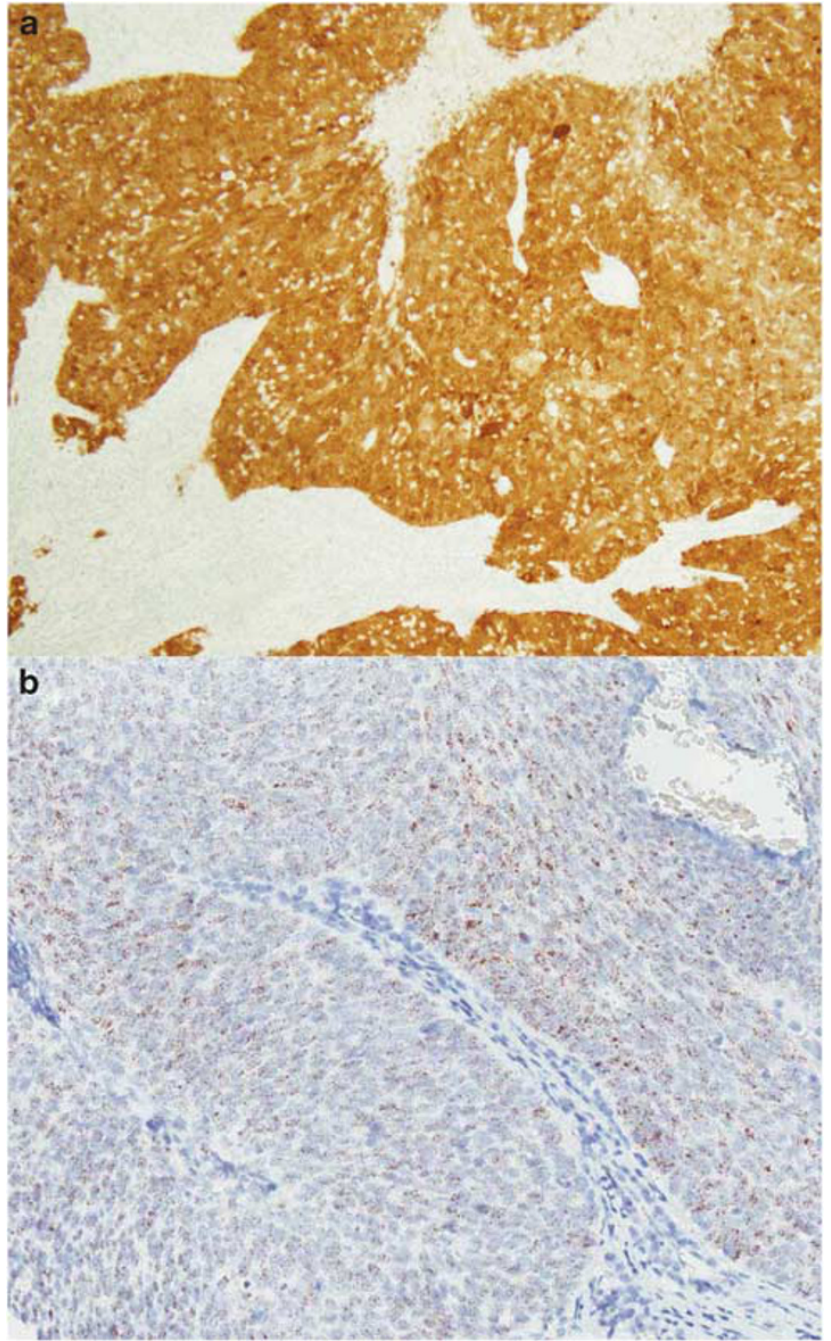

Figure 1 Oropharyngeal squamous cell carcinoma with (a) diffuse positive staining by p16 immunohistochemistry and (b) positive RNA in-situ hybridization for high risk HPV (HR HPV; $\mathbf{a}=\times 100$ magnification; $\mathbf{b}=\times 200$ magnification).

carcinoma or undifferentiated ( $P=0.019)$. All four of the non-keratinizing (Type 3) and non-keratinizing with maturation (Type 2) squamous cell carcinoma cases were positive for transcriptionally active HPV by RNA in-situ hybridization and reverse-transcriptase PCR.

\section{Discussion}

As HPV-related oropharyngeal squamous cell carcinoma has been identified as a distinct entity among head and neck squamous cell carcinoma with prognostic and management implications, it is critical to identify such cases in routine clinical practice and to differentiate them from the patients with non-HPV-related squamous cell carcinoma. ${ }^{7,19,20,26}$ Currently, there is no consensus on how to do so, and practices vary greatly from those performing no testing at all to those who perform p16 immunohistochemistry alone to those who use p16 immu- nohistochemistry followed by one or more HPVspecific tests on the p16-positive cases. There are extremely high correlation rates between the HPVspecific tests, especially those that detect transcriptionally active virus, and p16 immunohistochemistry, usually $>90 \%$. $^{1,11,15,23,25,27,31,32,35,36}$ Although many consider the detection of HR HPV E6/E7 mRNA on fresh tissue to be the gold standard for establishing a tumor as related to transcriptionally active $\mathrm{HPV},{ }^{20}$ for actual risk stratification, the real standard against which to judge these tests is patient survival. For risk stratification (as binary categorization of patients' tumors as 'favorable prognosis' or 'unfavorable prognosis'), all of these tests perform very well and essentially comparably. On the basis of this and also on practical issues, such as availability, ease of interpretation, and cost, some recommend just using p16 immunohistochemistry alone. ${ }^{11,37,38}$

One major critique of p16 immunohistochemistry for risk stratification in oropharyngeal squamous cell carcinoma is that there are a few equivocal cases (ie, cases where staining is not clearly positivestrong and diffuse-or negative). ${ }^{20}$ This is actually rather uncommon. ${ }^{11,25,32}$ p16 is overexpressed in tumor cells with transcriptionally active HPV because the viral E7 protein binds to the retinoblastoma protein, abrogating its repression of p16 transcription. As such, p16 is extensively overexpressed in the nucleus and cytoplasm of tumor cells, resulting in diffuse, strong signals by immunohistochemistry. However, in cases with partial staining, a specific cutoff to use for the binary classification of cases has not been clearly established or directly evaluated in the literature. There is a great deal of indirect evidence, however. Most investigators, because they acknowledge that HPVrelated squamous cell carcinomas should have extensive p16 expression, have simply applied high cutoffs, most often $70 \% .^{1,27}$ At this cutoff, numerous studies have shown p16 positivity to strongly correlate with improved tumor treatment response and with favorable survival rates. ${ }^{1,20}$ Other studies have used a $50 \%$ cutoff $^{11,25}$ and some $60 \%,{ }^{15}$ whereas many have not used any specific cutoff at all. ${ }^{24,16,35,36,39}$ Despite this variation, p16 positivity has been strongly prognostic in all of the studies. This is because most positive cases show close to $100 \%$ staining for p16; so regardless of the cutoff applied, the overwhelming majority of cases will be classified the same. However, approximately $5-15 \%$ of oropharyngeal squamous cell carcinomas will show only partial p16 immunoreactivity. ${ }^{32}$ For example, in a previously study of a large cohort of p16-positive oropharyngeal squamous cell carcinoma, 15 of $189(8 \%)$ had partial staining of less than $75 \%$ of tumor cells. ${ }^{11}$

Very few studies have actually examined partially p16-positive tumors to see what percentage or pattern of p16 staining actually correlates with the presence of transcriptionally active HPV. 


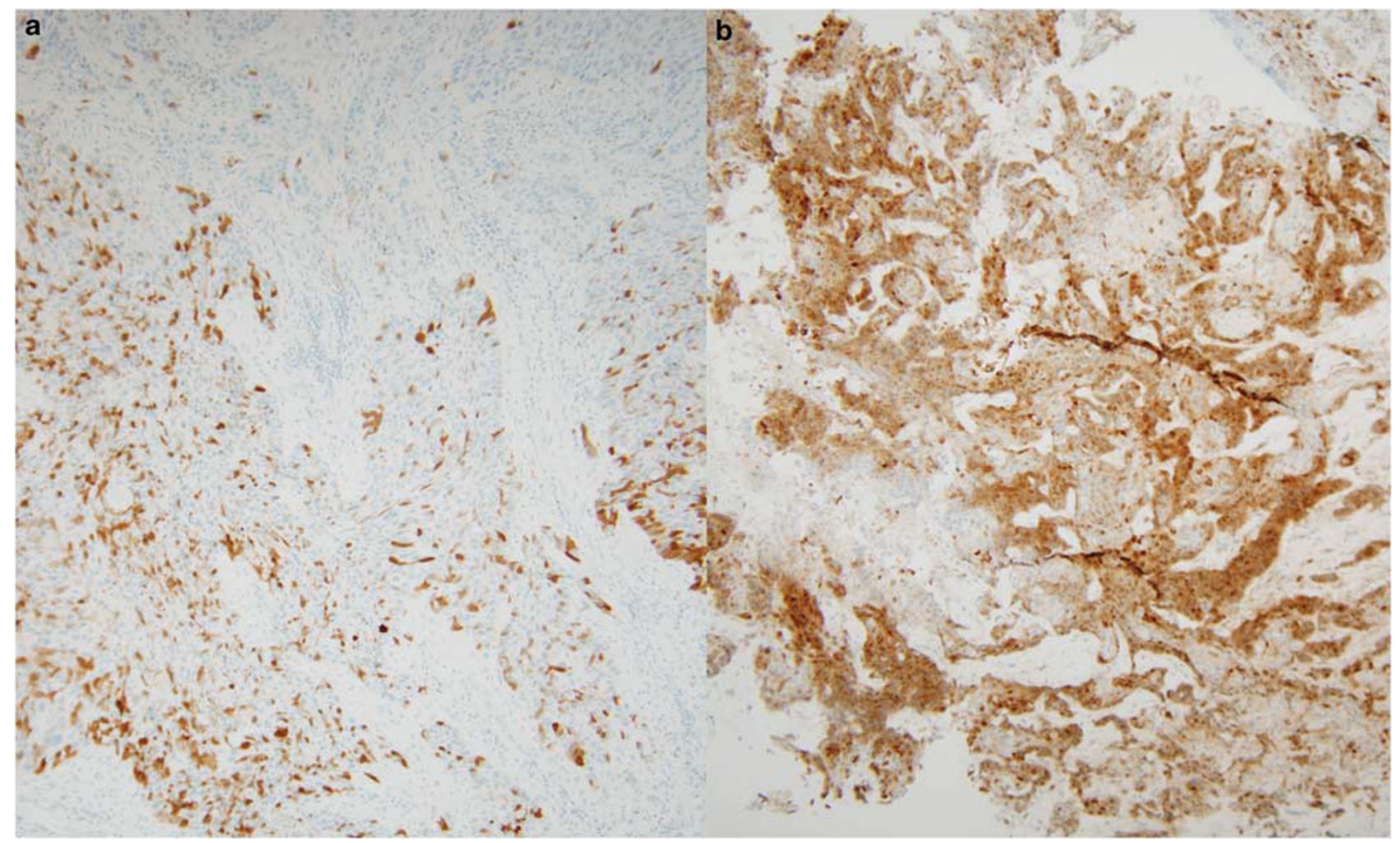

Figure 2 p16 staining differing by amount of confluent positive cells with (a) tumor showing only patchy staining, which is only minimally $(<25 \%)$ confluent, and (b) tumor showing significant ( $>25 \%$ ) confluent staining (both $\mathbf{a}$ and $\mathbf{b}=\times 100$ magnification).

Schlecht et al ${ }^{31}$ examined a sizeable cohort of head and neck squamous cell carcinomas by p16 immunohistochemistry and reverse-transcriptase PCR on fresh tissue for HR HPV E6/E7 mRNA. Among the 22 oropharyngeal squamous cell carcinoma cases tested by both assays, they found that only 1 of the 10 tumors with $>75 \%$ p16 staining was negative for HPV RNA by reverse-transcriptase PCR, whereas none of the 12 tumors with less than $75 \%$ p16 staining were HPV reverse-transcriptase-PCR-positive. Notably, their 'less than 75\%' staining group must have included cases with $0 \%$ staining, because they simply reported their lowest p16 staining cases as 'less than or equal to $25 \%$.' ${ }^{31}$ As such, it is not clear how many p16-positive, but with less than $75 \%$ staining, were present among those 12 cases.

In the current study, among the several hundred patients in the larger databases from which they were drawn, only 16 had p16 immunoreactivity, but with only partial staining. Of these 16 cases, the p16 $4+(>75 \%$ staining) cases and a subset of the p16 $3+$ (50 to $75 \%$ staining) cases harbored transcriptionally active HPV by two different HPV RNA assays, in-situ hybridization and reversetranscriptase PCR. The subset of p16 $3+$ cases that harbored HPV RNA all had significant amounts ( $>25 \%$ ) of confluent staining, where positive tumor cells were aggregated/back-to-back. The tumors with less than 50\% p16 staining consistently lacked HPV with only one case being HPV-positive, but by only one assay and with low expression levels. These findings validate the 70 or $75 \%$ cutoffs commonly utilized (and recommended) in the literature. They also show that for the p16 cases with $3+$ (50 to $75 \%)$ staining, there is a mixture of those with and without transcriptionally active HPV. An alternative to the $75 \%$ staining cutoff would be to use a $50 \%$ cutoff for positivity and then utilize the amount of confluent staining to segregate the cases with $3+$ (50 to $75 \%$ ) staining. A practical alternative may be to utilize HPV-specific testing for these 50-75\% positive cases. In the current study, the three $3+$ cases with HPV RNA all had $60 \%$ or more confluent staining (Figure 3), whereas the two $3+$ cases lacking HPV RNA both had $20 \%$ or less confluent staining. Also, although there was a trend towards stronger intensity of staining with higher amounts of p16 staining, several cases that were considered moderate intensity harbored HPV RNA. This argues that the distribution of p16 staining is much more important than the actual intensity.

There is ongoing debate about what test or combination of tests to use in routine practice to risk stratify patients with oropharyngeal squamous cell carcinoma, ${ }^{19,20,31}$ and one expects there to be ongoing research, discussion, and consensus gathering. All of the HPV-specific tests have shown the ability to identify patient groups with improved 


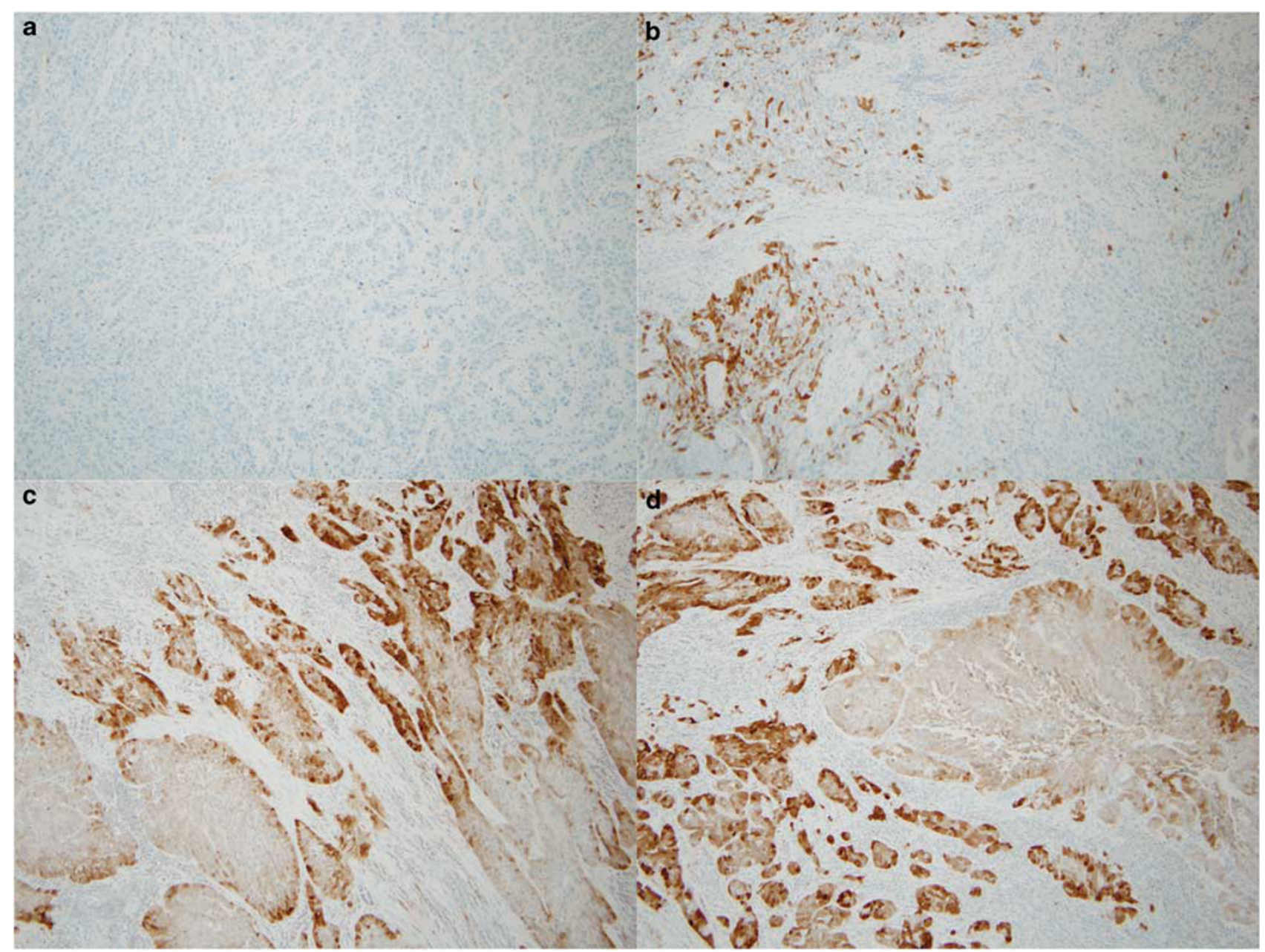

Figure 3 Varying degrees of p16 immunohistochemical staining: (a) tumor with no cells positive (only isolated, weak, non-tumor cell staining) (b) p16 staining with less than $25 \%$ of the tumor cells positive (c) staining with $26-50 \%$ of tumor cells positive (d) staining with $51-75 \%$ of tumor cells positive (only cells with positive nuclear and cytoplasmic staining considered positive; all images $\times 100$ magnification).

prognosis and treatment response, ${ }^{1,3,15,16,20,24}$ and p16 immunohistochemistry has also consistently been able to do so. ${ }^{1,10,25,40}$ Using p16 immunohistochemistry alone appears to be a very useful approach at this time for risk stratification of patients in routine practice. The major caveat is that, although p16 in oropharyngeal squamous cell carcinoma has extremely high correlation with the presence of transcriptionally active $\mathrm{HPV},{ }^{20,25}$ it does not directly demonstrate HPV in the tumors. For future treatments that may target HPV specifically, may attempt to interrupt viral protein-related signaling pathways, or may use vaccination or immune system modulation, tests that directly demonstrate the presence of HPV in tumors may be necessary.

Currently, p16 immunohistochemistry is widely used in practice; so, there is a need to better define what cutoff to use for positivity. This study directly addresses this question by assessing a cohort of partial p16-positive tumors for HPV DNA and E6/E7 mRNA by multiple methods. The results strongly support using a 70 or $75 \%$ cutoff for p16 positivity when using the E6H4 clone on formalin-fixed, paraffin-embedded tumor specimens. They also suggest that the use of a $50 \%$ cutoff is justified, if the pathologist then assesses for confluent staining for the cases in which there is between 50 and $75 \%$ staining, and limits positivity to those with more than $25 \%$ confluence.

\section{Acknowledgements}

We would like to acknowledge Jianping Li, BS, and Neha Dahiya, MD, MBA, of the Anatomic and Molecular Pathology Core Laboratory for their expert assistance with the p16 immunohistochemistry, and Kevin Selle, MBA, MT, HTL (ASCP), of the Barnes Jewish Hospital Clinical Immunohistochemistry Laboratory for his expert assistance with the DNA in-situ hybridization studies. The RNA in situ hybridization assays used in this study were funded by and performed by the coauthors from Advanced Cell Diagnostics, Hayward, CA, USA. 


\section{Disclosure/conflict of interest}

Co-authors JF, YL, and XM all have stock in Advanced Cell Diagnostics and stand to profit by any use of this testing through their company. The remaining co-authors have received nothing from the company and have no financial or other conflicts of interest to disclose.

\section{References}

1 Ang KK, Harris J, Wheeler R, et al. Human papillomavirus and survival of patients with oropharyngeal cancer. N Engl J Med 2010;363:24-35.

2 Gillison ML, Koch WM, Capone RB, et al. Evidence for a causal association between human papillomavirus and a subset of head and neck cancers. J Natl Cancer Inst 2000;92:709-720.

3 Adelstein DJ, Ridge JA, Gillison ML, et al. Head and neck squamous cell cancer and the human papillomavirus: summary of a National Cancer Institute State of the Science Meeting, 9-10 November 2008, Washington, D.C Head Neck 2009;31:1393-1422.

4 Chung $\mathrm{CH}$, Gillison ML. Human papillomavirus in head and neck cancer: its role in pathogenesis and clinical implications. Clin Cancer Res 2009;15:67586762 .

5 Chaturvedi AK, Engels EA, Pfeiffer RM, et al. Human papillomavirus and rising oropharyngeal cancer incidence in the United States. J Clin Oncol 2011;29:4294-4301.

6 Ramqvist T, Daliani T. An epidemic of oropharyngeal squamous cell carcinoma (OSCC) due to human papillomavirus (HPV) infection and aspects of treatment and prevention. Anticancer Res 2011;31:15151519.

7 Sturgis EM, Ang KK. The epidemic of HPV-associated oropharyngeal cancer is here: is it time to change our treatment paradigms? J Natl Compr Canc Netw 2011;9:665-673.

8 D’Souza G, Kreimer AR, Viscidi R, et al. Case-control study of human papillomavirus and oropharyngeal cancer. N Engl J Med 2007;356:1944-1956.

9 Stransky N, Egloff AM, Tward AD, et al. The mutational landscape of head and neck squamous cell carcinoma. Science 2011;333:1157-1160.

10 Rich JT, Milov S, Lewis Jr JS, et al. Transoral laser microsurgery (TLM) \pm adjuvant therapy for advanced stage oropharyngeal cancer: outcomes and prognostic factors. Laryngoscope 2009;119:1709-1719.

11 Lewis Jr JS, Thorstad WL, Chernock RD, et al. p16 positive oropharyngeal squamous cell carcinoma:an entity with a favorable prognosis regardless of tumor HPV status. Am J Surg Pathol 2010;34:1088-1096.

12 Chernock RD, El-Mofty SK, Thorstad WL, al. HPVrelated nonkeratinizing squamous cell carcinoma of the oropharynx: utility of microscopic features in predicting patient outcome. Head Neck Pathol 2009;3:186-194.

13 Braakhuis BJ, Snijders PJ, Keune WJ, et al. Genetic patterns in head and neck cancers that contain or lack transcriptionally active human papillomavirus. J Natl Cancer Inst 2004;96:998-1006.

14 Agrawal N, Frederick MJ, Pickering CR, et al. Exome sequencing of head and neck squamous cell carcinoma reveals inactivating mutations in NOTCH1. Science 2011;333:1154-1157.

15 Reimers N, Kasper HU, Weissenborn SJ, et al. Combined analysis of HPV-DNA, p16 and EGFR expression to predict prognosis in oropharyngeal cancer. Int J Cancer 2007;120:1731-1738.

16 Rischin D, Young RJ, Fisher R, et al. Prognostic significance of p16INK4A and human papillomavirus in patients with oropharyngeal cancer treated on TROG 02.02 phase III trial. J Clin Oncol 2010;28:4142-4148.

17 Licitra L, Perrone F, Bossi P, et al. High-risk human papillomavirus affects prognosis in patients with surgically treated oropharyngeal squamous cell carcinoma J Clin Oncol 2006;24:5630-5636.

18 Fakhry C, Westra WH, Li S, et al. Improved survival of patients with human papillomavirus-positive head and neck squamous cell carcinoma in a prospective clinical trial. J Natl Cancer Inst 2008;100:261-269.

19 Braakhuis BJ, Brakenhoff RH, Meijer CJ, et al. Human papilloma virus in head and neck cancer: the need for a standardised assay to assess the full clinical importance. Eur J Cancer 2009;45:2935-2939.

20 Schache AG, Liloglou T, Risk JM, et al. Evaluation of human papilloma virus diagnostic testing in oropharyngeal squamous cell carcinoma: sensitivity, specificity, and prognostic discrimination. Clin Cancer Res 2011;17:6262-6271.

21 Dayyani F, Etzel CJ, Liu M, et al. Meta-analysis of the impact of human papillomavirus (HPV) on cancer risk and overall survival in head and neck squamous cell carcinomas (HNSCC). Head Neck Oncol 2010;2:15.

22 Hong AM, Dobbins TA, Lee CS, et al. Human papillomavirus predicts outcome in oropharyngeal cancer in patients treated primarily with surgery or radiation therapy. Br J Cancer 2010;103:1510-1517.

23 Heath S, Willis V, Allan K, et al. Clinically significant human papillomavirus in squamous cell carcinoma of the head and neck in UK practice. Clin Oncol (R Coll Radiol) 2012;24:e18-e23.

24 Shi W, Kato H, Perez-Ordonez B, et al. Comparative prognostic value of HPV16 E6 mRNA compared with in situ hybridization for human oropharyngeal squamous carcinoma. J Clin Oncol 2009;27:6213-6221.

25 Ukpo OC, Flanagan JJ, Ma XJ, et al. High risk human papillomavirus E6/E7 mRNA detection by a novel in situ hybridization assay strongly correlates with p16 expression and patient outcomes in oropharyngeal squamous cell carcinoma. Am J Surg Pathol 2011;35:1343-1350.

26 Robinson M, Sloan P, Shaw R. Refining the diagnosis of oropharyngeal squamous cell carcinoma using human papillomavirus testing. Oral Oncol 2010;46:492496.

27 Singhi AD, Westra WH. Comparison of human papillomavirus in situ hybridization and p16 immunohistochemistry in the detection of human papillomavirusassociated head and neck cancer based on a prospective clinical experience. Cancer 2010;116:2166-2173.

28 Smeets SJ, Hesselink AT, Speel EJ, et al. A novel algorithm for reliable detection of human papillomavirus in paraffin embedded head and neck cancer specimens. Int J Cancer 2007;121:2465-2472.

29 Thavaraj S, Stokes A, Guerra E, et al. Evaluation of human papillomavirus testing for squamous cell carcinoma of the tonsil in clinical practice. J Clin Pathol 2011;64:308-312. 
30 Perrone F, Gloghini A, Cortelazzi B, et al. Isolating p16positive/HPV-negative oropharyngeal cancer: an effort worth making. Am J Surg Pathol 2011;35:774-778.

31 Schlecht NF, Brandwein-Gensler M, Nuovo GJ, et al. A comparison of clinically utilized human papillomavirus detection methods in head and neck cancer. Mod Pathol 2011;24:1295-1305.

32 Kong CS, Narasimhan B, Cao H, et al. The relationship between human papillomavirus status and other molecular prognostic markers in head and neck squamous cell carcinomas. Int J Radiat Oncol Biol Phys 2009;74:553-561.

33 Singhi AD, Stelow EB, Mills SE, et al. Lymphoepithelial-like carcinoma of the oropharynx: a morphologic variant of HPV-related head and neck carcinoma. Am J Surg Pathol 2010;34:800-805.

34 Tsang WYW, Chan JKC, Westra W. Lymphoepithelial carcinoma In: Barnes E.L, et al, (eds). World Health Organization Classification of Tumours-Pathology and Genetics-Head and Neck Tumours. IARC Press: Lyon France, 2005;176.

35 Weinberger PM, Yu Z, Haffty BG, et al. Molecular classification identifies a subset of human papilloma- virus-associated oropharyngeal cancers with favorable prognosis. J Clin Oncol 2006;24:736-747.

36 Weinberger PM, Yu Z, Kountourakis P, et al. Defining molecular phenotypes of human papillomavirus-associated oropharyngeal squamous cell carcinoma: validation of three-class hypothesis. Otolaryngol Head Neck Surg 2009;141:382-389e1.

37 Pfister DG, Ang KK, Brizel DM, et al. National Comprehensive Cancer Network clinical practice guidelines in oncology. Head and neck cancers. J Natl Compr Canc Netw 2011;9:596-650.

38 Langendijk JA, Psyrri A. The prognostic significance of p16 overexpression in oropharyngeal squamous cell carcinoma: implications for treatment strategies and future clinical studies. Ann Oncol 2010;21:1931-1934.

39 Weinberger PM, Yu Z, Haffty BG, et al. Prognostic significance of p16 protein levels in oropharyngeal squamous cell cancer. Clin Cancer Res 2004;10:56845691.

40 Fischer CA, Zlobec I, Green E, et al. Is the improved prognosis of p16 positive oropharyngeal squamous cell carcinoma dependent of the treatment modality? Int J Cancer 2009;126:1256-1262. 